ARTICLE

https://doi.org/10.1038/s41467-020-14445-3

\title{
Rain and small earthquakes maintain a slow- moving landslide in a persistent critical state
}

Noélie Bontemps ${ }^{1 \star}$, Pascal Lacroix (iD ${ }^{1}$, Eric Larose (1) ${ }^{1}$, Jorge Jara ${ }^{2}$ \& Edu Taipe (i] ${ }^{3}$

In tectonically active mountain belts, landslides contribute significantly to erosion. Statistical analysis of regional inventories of earthquake-triggered-landslides after large earthquakes $(\mathrm{Mw}>5.5)$ reveal a complex interaction between seismic shaking, landslide material, and rainfall. However, the contributions of each component have never been quantified due to a lack of in-situ data for active landslides. We exploited a 3-year geodetic and seismic dataset for a slow-moving landslide in Peru affected by local earthquakes and seasonal rainfalls. Here we show that in combination, they cause greater landslide motion than either force alone. We also show the rigidity of the landslide's bulk clearly decreasing during $\mathrm{MI} \geq 5$ earthquakes. The recovery is affected by rainfall and small earthquakes $(\mathrm{Ml}<3.6)$, which prevent the soil from healing, highlighting the importance of the timing between forcings. These new quantitative insights into the mechanics of landslides open new perspectives for the study of the mass balance of earthquakes.

\footnotetext{
${ }^{1}$ Univ. Grenoble Alpes, Univ. Savoie Mont Blanc, CNRS, IRD, IFSTTAR, ISTerre, 38000 Grenoble, France. ${ }^{2}$ Laboratoire de Géologie, Département des Géosciences, École Normale Supérieure, CNRS, UMR 8538, PSL Research University, Paris, France. ${ }^{3}$ OVI-INGEMMET, Arequipa, Peru. ${ }^{\star}$ email: noelie. bontemps@univ-grenoble-alpes.fr
} 
arge and shallow earthquakes $(\mathrm{Mw}>5.5)$ trigger widespread landsliding in mountainous areas ${ }^{1-3}$, thus contributing to the mass balance of earthquakes. Most of the earthquaketriggered landslides are activated co-seismically by moderate to large earthquakes (magnitude $>4$ ) ${ }^{4}$. Various mechanisms have been invoked to explain the co-seismic triggering of landslides: dynamic loading due to seismic shaking increases the shear stress applied to the sliding surface, and thus the shear forces can overcome the shear resistance ${ }^{5-7}$. The multiple ground motion cycles progressively weaken the soil by fracturing the rock mass ${ }^{8}$; eventually, if associated with high precipitation, small displacements along the sliding surface could also generate a rapid drop in shear resistance due to the crushing of the grains in the shearing plane. This reduction in volume can lead to a rapid increase in pore pressure if the sliding surface is in the water table, and hence potentially a co-seismic reactivation and/or a rapid triggering of the landslide ${ }^{9,10}$. This last mechanism known as undrained loading was observed in both fine grain rock ${ }^{10-12}$ and soil slides 9,13 , and can lead to the reactivation or the triggering of landslides.

In addition, some observations indicated different time scales in the delay between seismic shaking and landslide activation $^{1,14}$, often when the earthquake was combined with precipitations, the other main forcing of landslides. At the scale of a week, a change in groundwater conditions (pore pressure and/or permeability increase) can occur due to microfractures and cracks in the bedrock caused by the shaking ${ }^{15}$. The resulting changes in water content can take several days to reach the landslide's sliding surface, hence the landslide can occur several days later ${ }^{14,16}$. Increased rates of rapidly triggered landslides were also observed in various regions, months to years after major earthquakes $(\mathrm{Mw}>6.6)^{17}$. Slow-moving landslides can also be affected over the same time scales, with increased velocities observed in the years following a $\mathrm{Mw}=5.4$ earthquake ${ }^{18}$. A possible mechanism for these changes, which is corroborated by field surface observations, involves the decrease of rock strength due to earthquake-generated micro-/ macrofractures ${ }^{17}$. These fractures can then generate preferential paths for precipitation infiltration ${ }^{17,19}$ and/or increase hillslope failure due to the decreased mechanical strength of the rock ${ }^{19-21}$. The different time scales raise questions as to the relationship between shaking, precipitation, material damage, and/or permeability. The time scales of the healing processes in highly weathered media, where rainfall is usually the main factor triggering landslides ${ }^{22,23}$, are also currently unknown. Current hypotheses as to the physical processes behind how this earthquake-precipitation combination triggers landslides are based only on qualitative observations ${ }^{1,14,17,19}$. We still lack quantitative observations at the landslide-scale to confirm the mechanisms involved. In this study, we aimed to document those mechanisms using local information such as surface displacement and material rigidity, obtained from in situ measurements of a slow-moving landslide in an environment where earthquakes may be combined with seasonal differences in rainfall.

This study highlights the importance of the timing between earthquakes and precipitation, together with the role of small and medium magnitude earthquakes $(\mathrm{Ml}<4.5)$ in landslide kinematics and the recovery process of the soil's rigidity. We point out the damage of the soil generated by strong seismic shaking and explains the long-term impact of medium to large earthquakes on landslide triggering. Our results also show how small-shaking events can affect the landslide rigidity when combined with precipitations. They will indeed prevent the recovery of the rigidity of the soil with time.

\section{Results}

Context and experimental setup. The broad slow- to very slowmoving landslide of Maca (Fig. 1 and Supplementary Fig. 1) has been identified has a clay/silt compound slide with a rupture surface of uneven curvature ${ }^{24}$ and thus, belongs to the soil slide category ${ }^{25}$. This 60 million $\mathrm{m}^{3}$ landslide impacts a village in a rural area in the Colca Valley, southern Peru, in a very seismically active zone $e^{26,27}$. This area also experiences seasonal precipitations falling entirely between December and $\mathrm{May}^{24}$ (Fig. 2a). The first 8-12 $\mathrm{m}$ of the landslide are composed of a very permeable layer from a 10,000-year-old debris avalanche, whereas the underlying material corresponds to fine lacustrine deposits with a thickness $>50 \mathrm{~m}$. In the fastest part of the landslide, the sliding surface is located at least $40 \mathrm{~m}$ down from the surface, within the lacustrine deposits $^{24}$.

The landslide velocity estimated over the last 10 years is about $1.5 \mathrm{~m} \cdot \mathrm{yr}^{-1}$ in its fastest zone $\mathrm{e}^{18}$, and may reach up to $7 \mathrm{~m} \cdot \mathrm{yr}^{-1}$ during strong rainy seasons ${ }^{18,24}$ (Fig. 1a). The kinematics of the landslide is mainly driven by precipitations and by the river eroding its toe, but there exists a rainfall threshold above which deformation is triggered ${ }^{24}$. Regional earthquakes $(M w \leq 6)$ can also accelerate its motion in a co-seismic way, followed by a period of relaxation ${ }^{5}$. The landslide kinematics is therefore affected by both earthquakes and rainfall, but the mechanics of the material in the bulk of the landslide remains uncertain.

The persistence of the motion allows monitoring different physical parameters of the landslide's mechanics and their evolution with time. As a consequence, its unique situation in an area where both rainfalls and earthquakes combine, makes it of high interest to study the landslide's mechanics under seismic/ rainfall forcings. The kinematics of the Maca landslide is representative of a broad range of landslides, showing typical seasonal behaviors ${ }^{24,28-30}$, as well as the existence of a rainfall threshold to initiate the motion ${ }^{30-33}$ and similar pattern of motions than other landslides of the valley during earthquakes ${ }^{34}$. Its characteristics are typical of landslides in lacustrine deposits, in terms of velocity, geology, thickness, and mechanisms ${ }^{35-39}$. For all these reasons, this landslide has been intensively monitored since 2011.

In December 2015, a hut hosting a GPS and a broadband seismometer was installed on the fastest part of the landslide (Fig. 1a, Supplementary Figs. 1 and 2). These two instruments continuously monitor two geophysical parameters: the surface displacement of the landslide and the relative seismic velocity changes in the landslide body $(\mathrm{dv} / \mathrm{v})$ using ambient seismic noise ${ }^{40-42}$. This latter parameter is related to variations in soil density and/or rigidity 41,43 . In addition, GPS campaigns have been performed at the hut's location every 3 months since 2013, and were used to measure the overall landslide displacement between 2013 and 2015 at this specific location ${ }^{24}$.

Combined effect of rainfall and earthquakes on landslide dynamics. We first focused on the surface GPS displacement and the seismic activity in rainy and dry seasons.

Over the period of study, high seismic activity was recorded, with $165 \mathrm{Ml} 3.1$ to 5.5 earthquakes within a $50 \mathrm{~km}$ radius of the landslide. Two earthquakes significantly affected the landslide's kinematics over the period studied. The first one occurred on the 20 February 2016, during the rainy season, and the second on 15 August 2016 during the dry season. The magnitudes of these earthquakes were estimated by the Peruvian Geophysical Institute at 5.0 and 5.5, respectively, on the local magnitude scale ( $\mathrm{Ml})$, and their sources were located at $9 \mathrm{~km}$ and $11 \mathrm{~km}$ from the landslide, respectively (see Fig. 1b). The ground shaking caused by the August 


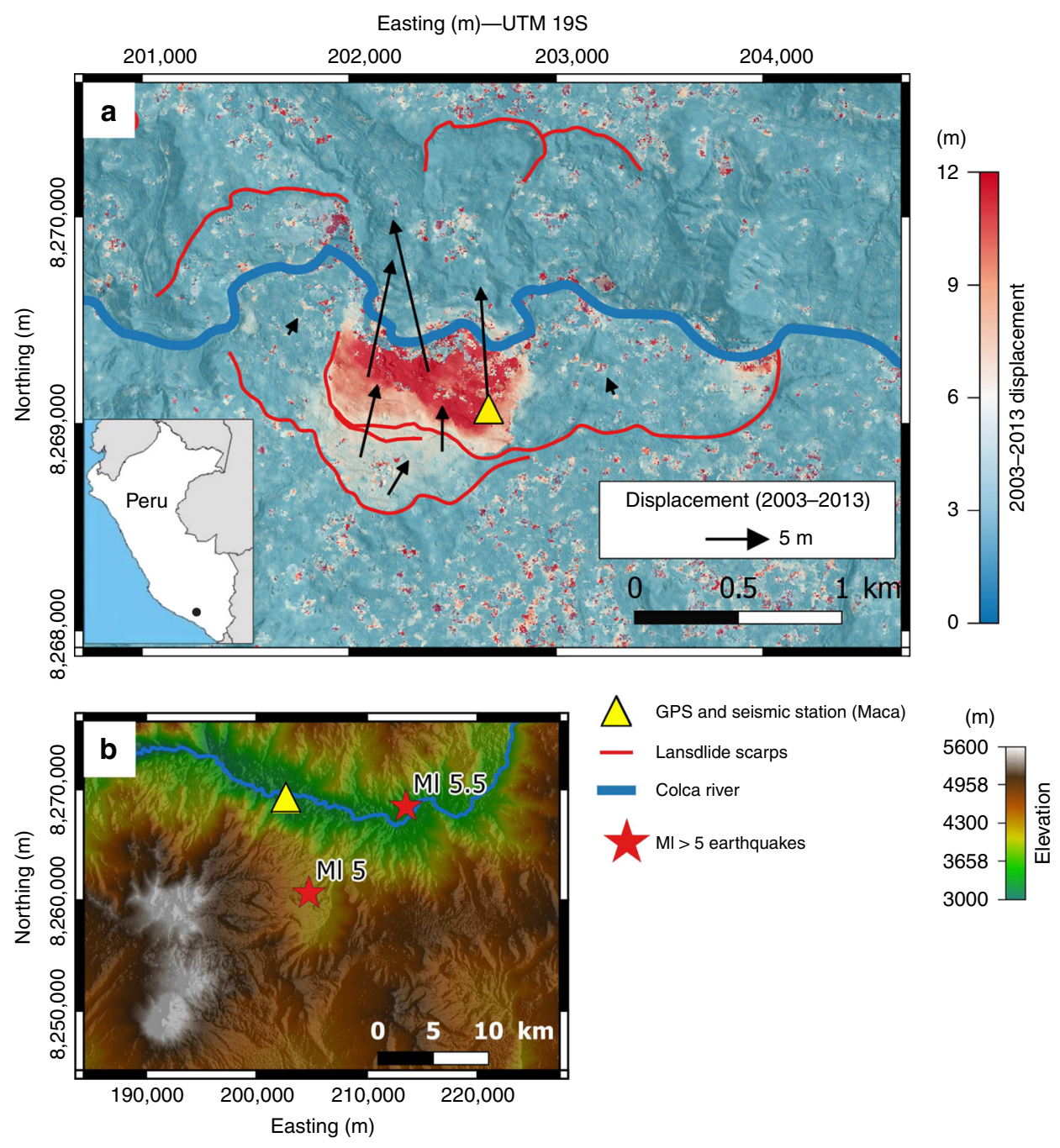

Fig. 1 The Maca landslide. a Cumulative displacement of the Maca landslide between 2003 and 2013 (from Bontemps et al. ${ }^{18}$ ). b Digital elevation model of a part of the Colca Valley. The red stars represent the epicenters of the MI 5.0 and the MI 5.5 earthquakes that occurred on 20 February and 15 August 2016, respectively. The yellow triangle indicates the location of the hut housing the GPS and seismic station on the Maca landslide.

2016 earthquake on the landslide was significantly more extensive than that caused by the February 2016 earthquake (approximated Peak Ground Velocity PGV app of $5.3 \mathrm{~cm} \cdot \mathrm{s}^{-1}$ compared with $3.5 \mathrm{~cm} \cdot \mathrm{s}^{-1}$ for the February earthquake- see Methods section).

As a result of the 15 August 2016 earthquake, the Maca landslide underwent a co-seismic slip of $1 \mathrm{~cm}$ followed by a relaxation period that lasted 30-40 days, during which the cumulated displacement was $11 \mathrm{~cm}$ (Fig. 2b, red curve). These coand post-seismic effects corroborate previous observations of the same landslide following a Mw6.0 earthquake, which also occurred during a dry season, the origin of which was located $20 \mathrm{~km}$ from the landslide ${ }^{5}$. After the February earthquake, the Maca landslide underwent co- and post-seismic slippage of $80 \mathrm{~cm}$ over 5 months. This displacement is much greater than that recorded after the August earthquake even though the estimated shaking generated at the landslide's location by the February earthquake was weaker than in August. This observation suggests that rainfall plays a major role in how an earthquake triggers/ activates a landslide, and hence reveals a strong combination between the two different forcing events.

To validate this hypothesis, we must eliminate the possibility that the rain alone could have generated equivalent landslide displacements during the 2016 wet season. To do so, we focused our attention on the 2014 and 2017 rainy seasons and the displacements observed over these periods.

The 2014 rainy season was comparable to the 2016 season in terms of precipitation recorded (Fig. 3). However, seismic activity was much lower in 2014, with only 44 earthquakes with a PGV > $0.01 \mathrm{~cm} . \mathrm{s}^{-1}$, compared with 99 in $2016\left(0.01 \mathrm{~cm} . \mathrm{s}^{-1}\right.$ corresponds to the minimum PGV measured on the landslide among all the local earthquakes detected by the IGP network in the Colca Valley). Interestingly, the landslide displacements measured in 2014 were almost zero. Moreover, the rainfall recorded in 2017 (a year once again with much lower seismicity than 2016) was more than twice that recorded for 2016 (see Fig. 3). Nevertheless, the displacements in 2017 were only half those recorded during the 2016 rainy season. This difference in displacements between the different wet seasons can therefore be attributed to the greater seismic activity in 2016 than in 2017 or 2014 (Supplementary Fig. 10). Thus, our results represent the combined effect of earthquake shaking and precipitations on the acceleration of a slow-moving landslide, similar to what has been observed with rapid landslides triggered following large earthquakes ${ }^{17}$. These observations indicate that the combination of earthquakes and precipitations leads to greater landslide motion than either phenomenon alone. Hereafter, we take advantage of the 


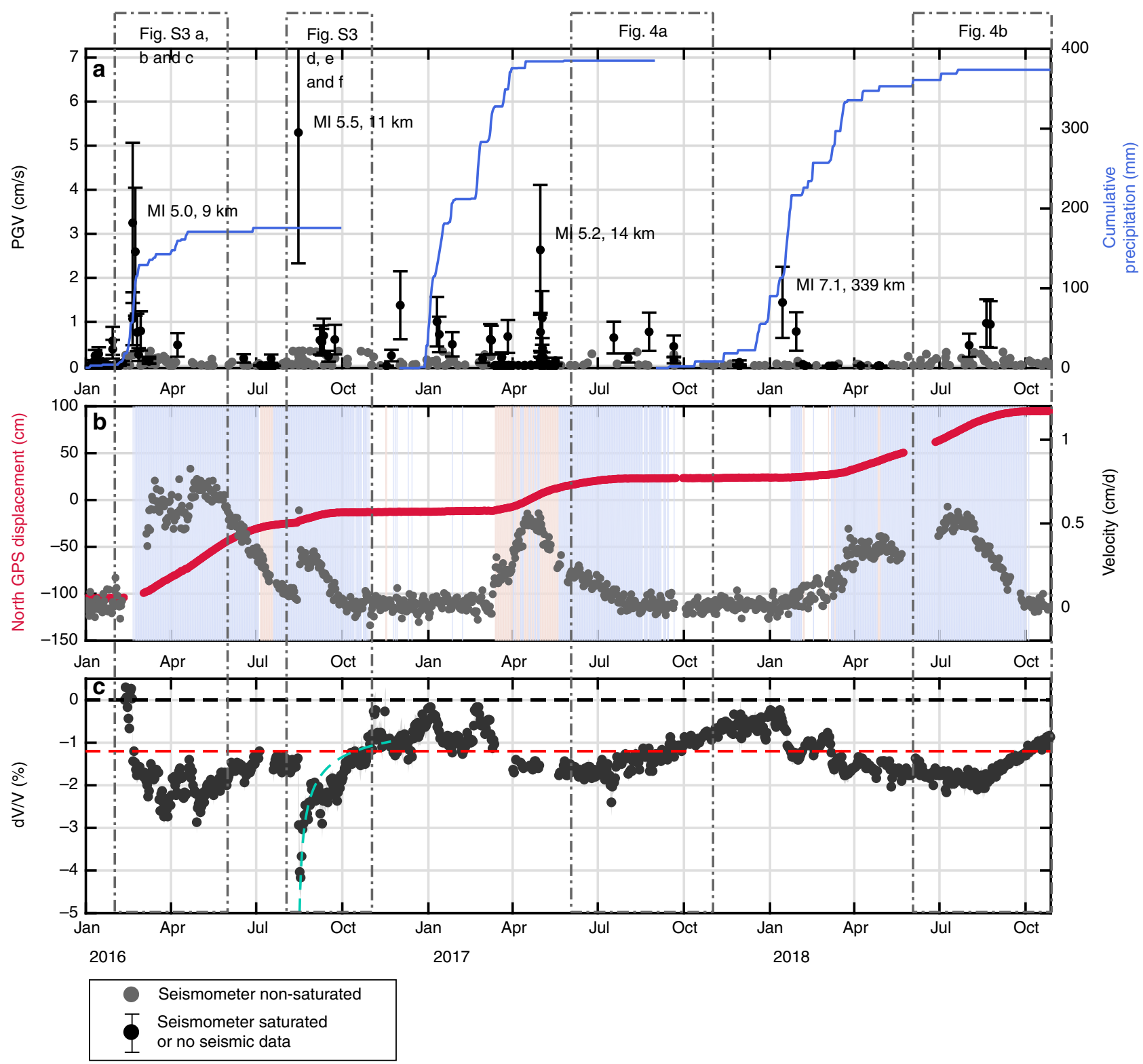

Fig. 2 Comparison of landslide displacement and dv/v induced by earthquakes and precipitation. a Seismicity reported by the Peruvian Geophysical Institute (IGP) for earthquakes with PGV above $0.01 \mathrm{~cm} \cdot \mathrm{s}^{-1}$ (see SI) on the landslide (gray dots), and cumulative rainfall over the rainy season (solid blue line). Earthquakes strong enough to saturate the seismometer located on the landslide or earthquake where no records were available due to problems with the seismometer are indicated by black dots. For significant earthquakes, magnitudes and distances to the Maca landslide were indicated. $\mathbf{b}$ Time series of the Maca GPS North cumulative displacement (red) and velocity (gray) at a 1-day sampling rate. Blue zones represent periods were the dv/v in under $-1.2 \%$, and red zones represent periods were the $\mathrm{dv} / \mathrm{v}$ is likely under $-1.2 \%$ but gaps in the seismic data exist. c Changes to relative seismic velocity of the material determined by comparing daily seismic noise correlograms in the $3-8 \mathrm{~Hz}$ frequency range (black), which have a depth sensitivity of up to $40 \mathrm{~m}$ (see Supplementary Figs. 12 and 13). Gaps in the dv/v time series correspond to missing records. The horizontal black dashed line is the surface wave velocity on the first day of our study period. The red horizontal dashed line is an empirical threshold used in the text $(-1.2 \%)$ under which the landslide is in a critical state. The logarithmic green curve represents the recovery function proposed by Richter et al. ${ }^{48}$. Boxes indicate part of the graphic that has been enlarged either in Supplementary Fig. 3 or in Fig. 4. Close-up of the years 2017 and 2018 are displayed, respectively, in the Supplementary Figs. 4 and 5.

persistence of the slow-moving landslide movement to study the mechanism producing this combined effect.

An $\mathrm{Ml}=5$ earthquake causes considerable damage to the unstable mass. We investigated the existence and causes of any soil alterations, based on measurements of the soil's rigidity over time thanks to ambient seismic noise correlation methods ${ }^{41,43}$ (see Methods section).

Following the Ml 5.5 August 2016 earthquake, the surface wave velocity in the $3-8 \mathrm{~Hz}$ frequency range dropped co-seismically by more than 2\% (Fig. 2c and Supplementary Fig. 3f). Investigation of the sensitivity of the surface waves at different frequencies and depths indicated that the $3-8 \mathrm{~Hz}$ range corresponds to a depth sensitivity of $\sim 40 \mathrm{~m}$ (see Methods section and Supplementary Figs. 12 and 13). The variations observed are therefore located in the landslide's body.

We examined the influence of three different mechanisms, i.e., undrained loading ${ }^{10}$, the variation of the water table $e^{44}$, and the damage of the soil due to earthquake shaking ${ }^{17}$, upon the $\mathrm{dv} / \mathrm{v}$ in the $3-8 \mathrm{~Hz}$ frequency range, thanks to poroelastic models ${ }^{45,46}$. 


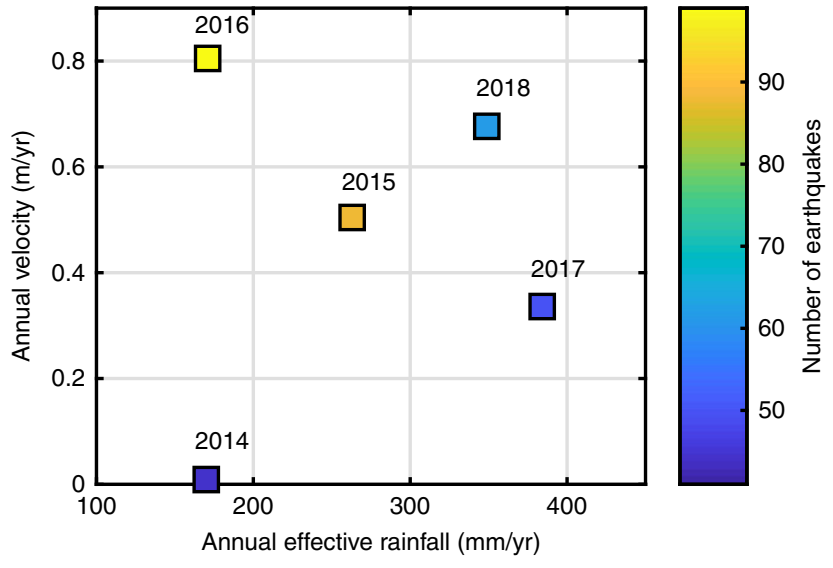

Fig. 3 Annual landslide velocity as a function of effective annual rainfall. Colors indicate the number of earthquakes with PGV at the landslide location above $0.01 \mathrm{~cm} . \mathrm{s}^{-1}$. See SI and Supplementary Fig. 6 for more information. The effective annual rainfall corresponds to the cumulative effective precipitation between December until mid-August of each year. The cumulative displacement for each year corresponds to the total displacement between the first and the last date of the rainy season were the landslide's velocity is above a certain threshold (set at $0.039 \mathrm{~m} . \mathrm{yr}^{-1}$ ). Earthquakes are counted only in between 2 weeks prior to the acceleration of the landslide, up to when the motion ceases in each rainy season. The displacement and seismicity following the August 2016 earthquake are not taken into account for 2016. These periods are summarized in the Supplementary Fig. 6 and Supplementary Note 1.

The effect of undrained cyclic loading ${ }^{10}$ was estimated by modeling the liquefaction of the sliding surface, i.e., a strong reduction of the S-wave velocity near the sliding surface, between 38 and $40 \mathrm{~m}$ (see Supplementary Fig. 14a). Our model predicts strong $\mathrm{dv} / \mathrm{v}$ variations at low frequencies, with a maximum variation of $\sim-3 \%$ around $3 \mathrm{~Hz}$ (Supplementary Fig. 14b). Our observations of the $\mathrm{dv} / \mathrm{v}$ variations at different frequencies the day of the August 2016 earthquake do not correspond to the model predictions (Supplementary Fig. 14b). Indeed the observed drop is overly low around $3 \mathrm{~Hz}$ and too high above $5 \mathrm{~Hz}$ to be explained by undrained loading (Fig. 2 and Supplementary Figs. 14b, h)

At first sight, the possible effects of variations in water table level on the observed $\mathrm{dv} / \mathrm{v}$ could be neglected as the earthquake occurred in the dry season, several months after the last precipitations, implying a lower saturation of the soil. However, to be certain, we modeled a 1-m elevation of the perched aquifer at $10-\mathrm{m}$ depth (see Methods section). This modeling could only explain a dv/v drop of $0.04 \%$ i.e., 2 orders of magnitude below the dv/v drop observed between 3 and $8 \mathrm{~Hz}$ (Fig. 2 and Supplementary Fig. 3).

The co-seismic drop in velocity can therefore be attributed predominantly or even completely to damage to the soil $45,47-49$, due to the opening of new or pre-existing cracks ${ }^{47,48,50-52}$.

Almost immediately after earthquake shaking, the $\mathrm{dv} / \mathrm{v}$ was seen to recover. This recovery was clearly visible, for instance, with the August 2016 earthquake (Fig. 2c and Supplementary Fig. 3f). This healing phase can be interpreted as the recompaction of the soil as fractures close, and the grains cement together, reflecting a viscoelastic response of the soil ${ }^{47,48,50-52}$. This slow healing was also observed at laboratory-scale, where it is referred to as slow dynamics ${ }^{53}$. Previous observations of the $\mathrm{dv} /$ $\mathrm{v}$ recovery after an earthquake show that it often evolves logarithmically over time $47,48,51$. A similar pattern was also observed here, with recovery of the pre-earthquake soil state around one and a half months after the Ml 5.5 earthquake in
August 2016 (Fig. 2c, light-green logarithmic curve and Supplementary Fig. 3f). However, recovery is questionable during the wet season, as we cannot separate it from the drainage process. This becomes even more complicated when smallearthquake activity is high, as we will see in the next sections.

Recovery during wet seasons reveals the mechanism causing the combined effect. To better understand the combined role of water and earthquakes, we focused on the Ml 5.0 February 2016 earthquake, which occurred during a rainy season (Fig. 1c and Supplementary Fig. 3c).

The drop in $\mathrm{dv} / \mathrm{v}$ for this earthquake was smaller than that measured in August 2016, possibly due to the difference in shaking intensity between the two events. However, in contrast to the event of August, the dv/v continued to decrease for several weeks after the Ml 5.0 event. As the surface wave velocity depends on the rigidity of the soil, we interpreted the co-seismic drop observed as soil damage due to the strong shaking, just like during the August earthquake (see Supplementary Fig. 14b). The difference in $\mathrm{dv} / \mathrm{v}$ behaviors in the weeks following the earthquake can be explained by a transient increase in soil density and/ or decrease in rigidity due to an augmentation of the water content in the lacustrine deposit. Indeed, the damage to the different ground layers, generated by the strong shaking associated with the February earthquake could have promoted water infiltration at depth. These observations provide quantitative measurements of the damage process which was qualitatively reported in a previous study ${ }^{17}$.

In addition, the movement of the landslide in itself favors the formation of cracks and fissures in the soil, which produce or amplify preferential water infiltration paths ${ }^{54-57}$. Following water infiltration, the activity of the landslide can be self-sustained. As a result, the combined effect of earthquakes and rainfall is amplified on slow-moving landslides.

Effect of small ground shaking on the landslide dynamics. Several questions can be raised related to the conditions (shaking limits and rainfall amounts) activating this damage/recovery process. To address these questions, we will now focus on periods with small to moderate seismic shaking, i.e., from June to endOctober of 2017 and 2018 where 121 events were recorded, all with PGV inferior to $1 \mathrm{~cm} \cdot \mathrm{s}^{-1}$ (Fig. 4).

During the period of observations, we noted that almost every time the $\mathrm{dv} / \mathrm{v}$ dropped below a certain threshold (empirically set at $-1.2 \%$ ), the landslide entered into motion (Fig. $2 c$, red horizontal line), i.e., was in the "critical regime." Once the $d v / v$ recovered and exceeded this threshold once again, the landslide slowed down and eventually stopped, entering the "stable regime."

Interestingly, the recovery phase, defined by the time at the end of the rainy season when the dv/v started to return to baseline, occurred later in 2018 than in 2017 (Fig. 4a, b). More precisely, in 2017, the dv/v recovered from mid-July, several months after the last precipitations, as the unstable mass dried out and its rigidity increased (Fig. 4a). In contrast, recovery in 2018 only started at the end of August, 1 month later than the previous year (Fig. 4b). This difference in $\mathrm{dv} / \mathrm{v}$ recovery could neither be attributed to a difference in cumulative precipitation (Fig. 2a), nor a delay in the rainy season (both rainy seasons were almost finished by the end of April), nor due to large seismic events (the number of events with large Peak Ground Velocity (PGV) was even higher in 2017). The Ml 7.1 that struck the Peruvian coast in January 2018, does not appear to have caused the difference either, as it occurred at the beginning of the wet season and no co-seismic variations of the surface wave velocities were observed at the seismic station. 
a
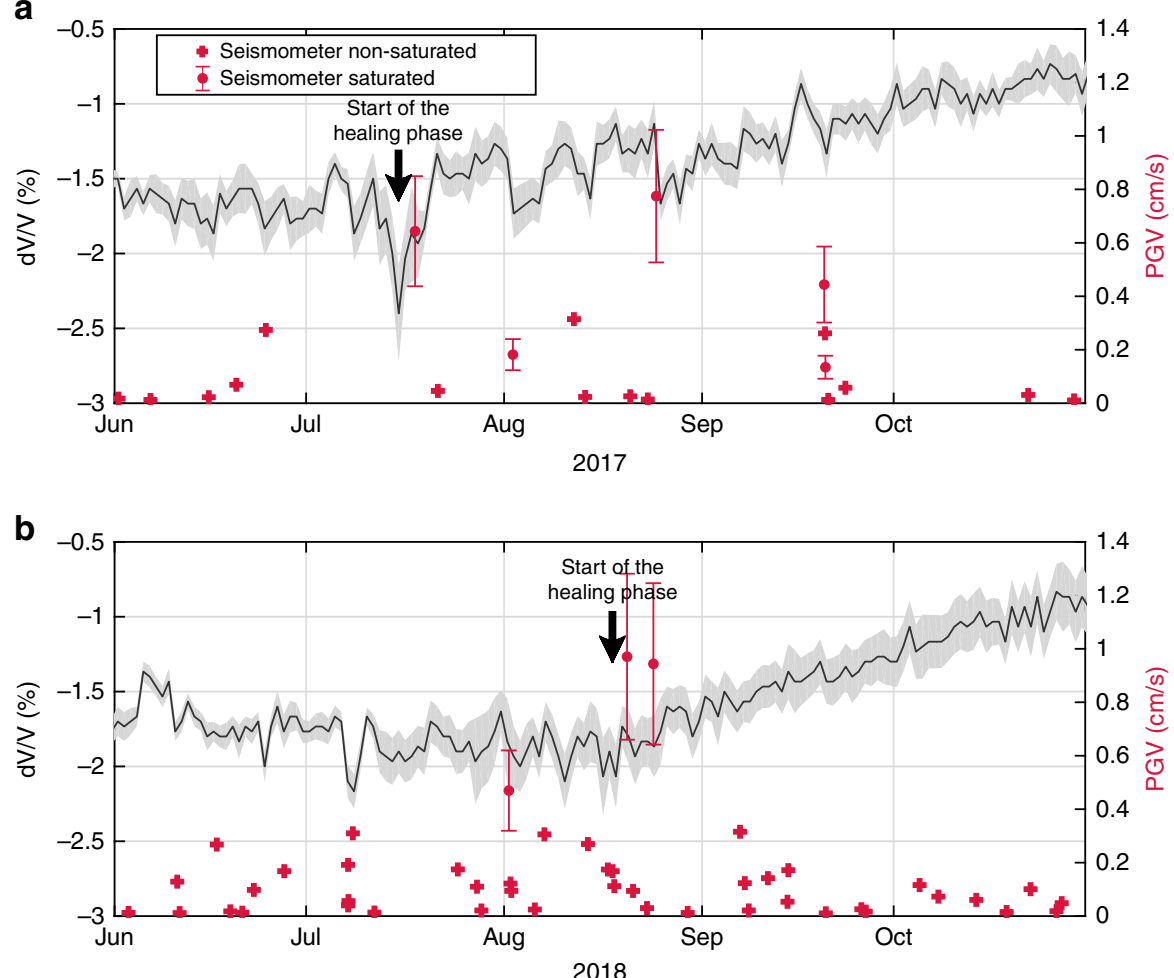

Fig. 4 Comparison of the recovery of the dv/v at the end of the $\mathbf{2 0 1 7}$ and $\mathbf{2 0 1 8}$ wet seasons. dv/v variations in the landslide material, obtained by comparing daily seismic noise correlograms in the 3-8 Hz frequency range in 2017 (a) and 2018 (b), together with all earthquakes reported by the IGP institute in Peru that have a PGV recorded at the landslide site above $0.01 \mathrm{~cm} \cdot \mathrm{s}^{-1}$ (cross mark) in 2017 (a) and 2018 (b). In addition, the PGV of earthquakes strong enough to saturate the seismometer placed on the landslide were estimated (dots) (see Methods for details).

The only remaining difference between 2017 and 2018 is the rate of low-magnitude earthquakes, which was greater at the end of the rainy season in 2018 than in 2017. Indeed, 30 seismic events of low ground motion $\left(\mathrm{PGV}<1 \mathrm{~cm} . \mathrm{s}^{-1}\right)$ were recorded between June and the end of August 2018, compared with only 13 earthquakes in 2017 during the same period (see Fig. 4). This difference suggests that the recovery phase in 2018 was delayed due to the intense seismic activity at the end of the rainy season. Hence, while water is stored in the landslide body, even small earthquakes can alter the landslide kinematics by limiting recovery processes, and thus keeping the landslide in the critical regime.

Note that at the end of August 2018, two large earthquakes with a PGV estimated close to $1 \mathrm{~cm} \cdot \mathrm{s}^{-1}$ occurred. This PGV is higher than any previously recorded in or estimated for 2018. Nevertheless, these earthquakes had no influence on the $\mathrm{dv} / \mathrm{v}$ and did not prevent the initiation of the recovery phase (Fig. 4b). At the end of August, the water content in the landslide was lower than between May and July due to sparse and low precipitation after the month of May 2018 (Fig. 2a). We therefore hypothesize that the impact of the low PGV on the landslide's rigidity decreases when water content in the soil also drops, eventually allowing the $\mathrm{dv} / \mathrm{v}$ to increase and initiation of the healing phase. Three mechanisms can be invoked to explain this smallearthquake effect. The shaking can break recent/weak bonds between the elements of the highly unconsolidated granular material (i.e., clay, siltstone, shale), which include chemical and capillary bonds ${ }^{58,59}$. It can also generate fluid circulation and alter pore water pressure during the wave train, or slightly alter the arrangement of unconsolidated grains. These three effects, individually or combined, can maintain the landslide in its critical state.

\section{Discussion}

Our results show that the combination of earthquakes and rainfall affects the rigidity of the Maca landslide. These observations allowed us to schematize the mechanics of a slow-moving landslide exposed to rainfall and earthquakes (Fig. 5): once the rigidity of the landslide drops below a defined threshold, deformations and displacements are triggered and the landslide enters a critical regime. Precipitations maintain the rigidity of the landslide below the threshold. In addition, in the critical regime, landslide displacement may also induce additional damage and loss of rigidity, meaning that the landslide is also partially self-sustaining. Once the rain-related water infiltration stops, the healing phase can start and landslide displacement will come to an end until the next forcing capable of triggering displacements (see Fig. 5 for a summary).

Our results also show how small-shaking events $\left(\mathrm{PGV}<1 \mathrm{~cm} . \mathrm{s}^{-1}\right.$ corresponding mainly to $\mathrm{Ml}<4.5$ in this region) can alter landslide rigidity and hence, its kinematic behavior over time. Indeed, small events combined with precipitation can maintain the low rigidity, preventing the unstable mass from recovering. Possible causes of this effect include prevention of the creation and/or breaking of existing chemical and/or capillary bonds between the elements of the highly unconsolidated granular material ${ }^{58,59}$, rearranging the grains, and/or increasing the pore pressure. To summarize, the landslide remains in a critical regime for longer than if small earthquakes had not occurred, as its rigidity stays below a certain critical threshold. In this context, the density of earthquake occurrence is a key parameter determining whether the landslide remains in a critical state.

The result of this study not only confirm previous observations relating to the combined effect of rainfall and earthquakes on either slow-moving landslides ${ }^{60}$, rapid landslides ${ }^{17}$ or rockfall 


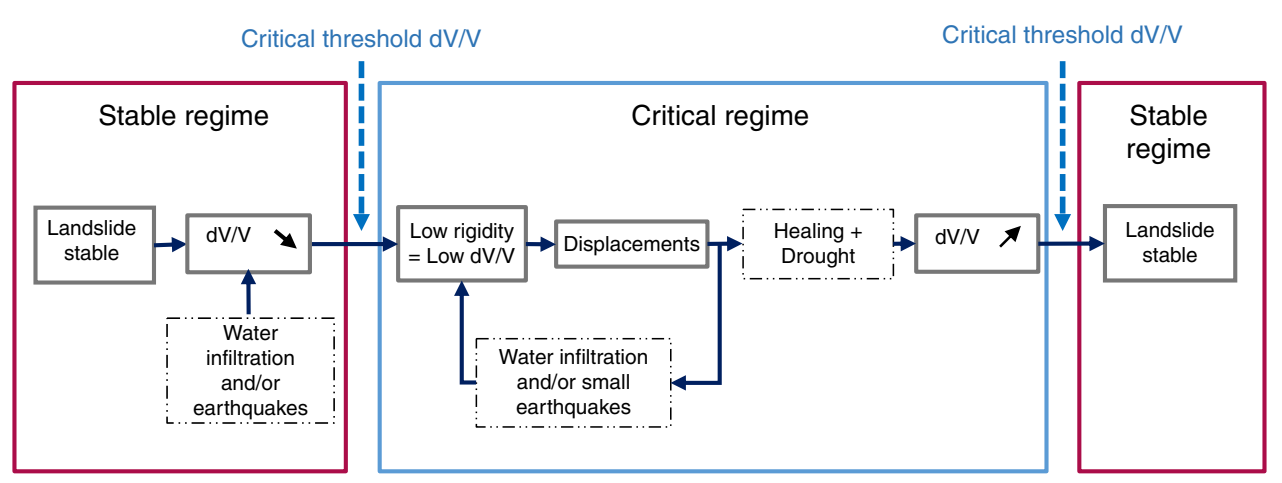

Fig. 5 Schematic representation of the different forcings affecting the slow-moving Maca landslide.

activity $^{61}$, but also provided quantitative data based on the $\mathrm{dv} / \mathrm{v}$ which support the previous hypothesis that soil damage causes this combined effect ${ }^{17}$. Soil damage, interpreted as the creation of micro-/macrofractures as a result of earthquake shaking, generates preferential paths for water infiltration and thus impacts landslide motion after an earthquake until the soil has completely healed. This mechanism would also explain the observations of rainfall threshold variation observed throughout the world after medium to large magnitude earthquakes ${ }^{18,62,63}$.

Even though these observations were obtained on a single landslide owing to the uniqueness of the site in terms of monitoring techniques and to the difficulty to maintain such monitoring over the years, previous measurement at this site showed the representativeness of the Maca landslide in terms of kinematics during earthquakes ${ }^{34}$ and seasonal rainfall forcings ${ }^{24,28-30}$. The Maca landslide is also similar to other landslides with regard to its geology, velocity, thickness, and mechanisms $s^{35-39}$. Furthermore, the processes highlighted here (damage and healing) are observed at large scale 47,48 and in all types of materials in laboratory experiments ${ }^{53,64}$. For these reasons, the mechanisms highlighted here are not specific to the Maca landslide but provide important information on the earthquake/rainfall combination on landslides in general. We should note, however, that quantitative differences should certainly exist between different landslides with different geology, thickness, and pore saturation.

These results help to better understand landslide forcing mechanisms and the strong combination between earthquakes and precipitations. This analysis has considerable implications both for landslide prediction and for the long-term impact of earthquakes on landscape evolution. The findings presented here support the idea that medium-intensity earthquakes $(\mathrm{Ml}<5.5)$ can also accelerate landslides, and that their impact will be greater when precipitations are recorded before or just after the event. These observations also highlight the strong impact of cumulated small earthquakes (Ml 3.2-3.6) combined with a high water content that prevents the landslide from recovering its rigidity, maintaining the unstable mass in a critical regime and enhancing displacements. This observation underlines the importance of the temporality between precipitations and earthquakes on triggering landslides, and consequently on the mass balance of earthquakes. Finally, this study also highlighted the importance of considering smaller earthquakes and slow-moving landslides when determining the mass balance of mountain building.

\section{Methods}

GPS processing. Fifty-five continuous GPS (cGPS) recordings were processed from various networks in the Andean region, South America and Nazca Plates (see Supplementary Fig. 7 in Supplementary Information). Thirty-three stations were installed and are maintained in Southern Peru and Northern Chile as part of the following projects: Integrated Plate Boundary (IPOC, www.ipoc-network.org), LIA-MB (www. lia-mb.net), CAnTO (www.tectonics.caltech.edu), CSN (www.csn.uchile.cl), and CAP (www.unavco.org). The remaining stations are part of the International GNSS Service (IGS, www.igs.org) global network. Data were processed using the double-difference method in GAMIT $10.6^{65}$, choosing the ionosphere-free combination and setting the ambiguities to integer values. Precise orbits from IGS, precise EOPs from the IERS bulletin B, IGS tables describing the phase center of the antennas, FES2004 oceantidal loading corrections, and atmospheric loading corrections (tidal and non-tidal) were used. One tropospheric Zenith delay parameter was estimated every $2 \mathrm{~h}$, and one pair of horizontal tropospheric gradients were determined per 24-h session using Vienna Mapping Functions (VMF1) ${ }^{66}$. These estimations allow the tropospheric delay to be mapped in the perpendicular direction, with a priori ZHD derived from pressure and temperature values from VMF1 grids. The daily solutions and position time series were obtained using PYACS software ${ }^{67}$, mapped first onto the ITRF 2008 reference frame ${ }^{68}$ and then onto the South American plate, using a fixed pole ${ }^{69,70}$.

Landslide velocity computation. To reduce noise when computing the velocity of the landslide at the location of the Maca GPS station, the displacement was averaged over a 5-day moving window. However, to reduce the smoothing effect and provide more realistic velocities after the August 2016 earthquake, the velocity was not smoothed for the 2 days following the earthquake.

Seismic data and ambient seismic noise processing. A Noemax (c) seismic station was used for this study. It has three components and a natural frequency of $4.5 \mathrm{~Hz}$. This seismometer includes an electronically-compensated instrumental correction allowing a relatively flat response between $0.1 \mathrm{~Hz}$ and about $50 \mathrm{~Hz}$.

The ambient noise in the frequency bands studied in Maca was mostly caused by vehicles on the main road located near the landslide, the river at the toe of the landslide and wind. These sources of noise can be considered stable in time only when the 24-h correlations are averaged, computed over each day as explained hereafter.

Single station cross-correlation was performed on the three possible pairs of components $^{51}$, i.e., North-East, vertical-East, and Vertical-North. To do so, hourlong records were spectrally whitened between 0.2 and $35 \mathrm{~Hz}$ to equalize the frequency content of the ambient noise ${ }^{43}$. The seismic signal was then normalized in amplitude using the clipping method such that the signal-to-noise ratio did not exceed three times its standard deviation. The main objective of this step was to attenuate the statistical weight of large events, such as earthquakes, compared with other events making up the ambient noise. The hour-long records were then correlated for the three possible pairs of components separately.

The next step was to filter the correlograms to enhance the signal-to-noise ratio by applying a Singular Value Decomposition-based Wiener filter ${ }^{71}$. The parameters used for this filter were $K=7, L=7$, the filter orders applied to the vertical and horizontal dimensions, respectively, and the number of first singular values was $N=30$. Finally, correlations were averaged over each day in order to increase the signal-to-noise ratio and to eliminate dv/v sub-daily variations due to source variations during the day. However, even though the clipping reduces the impact of earthquakes on the ambient noise correlation, they will slightly modify hourly correlations and thus daily correlations by acting as noise sources that are not constant with time. The direct consequences will be a decorrelation of the daily correlations with regard to the reference during the stretching step and thus an increase of $30 \%$, on average, of the $\mathrm{dv} / \mathrm{v}$ uncertainties compared with days with less seismicity.

Daily correlations were then compared with each other to track relative velocity changes using the stretching method ${ }^{72,73}$ applied to each component pair separately over the frequency band 3-8 Hz. The reference value for each stretch was obtained by averaging daily cross-correlation over the whole period of study. Stretched parts of the coda were selected between [ $-14 \Delta t: 2 \Delta t]$ and $[2 \Delta t: 14 \Delta t]$ seconds, i.e., $[-2.8:-0.4]$ and [0.4: 2.8$]$ seconds in the $3-8 \mathrm{~Hz}$ frequency band, to remove the autocorrelation of the noise source which has a duration $\Delta t=1 / \Delta f$. Here, we removed $2 \times \Delta t$ to be certain that the source noise is not used in the stretching step (Supplementary Fig. 8). Consequently, analysis mainly focused on 
scattering of surface waves (Rayleigh and possibly Love waves) in the strongly heterogeneous medium.

To decrease the signal-to-noise ratio, the $\mathrm{dv} / \mathrm{v}$ was averaged over the three directional correlation pairs. The absolute error of $\mathrm{dv} / \mathrm{v}$ was estimated from the correlation coefficient obtained by the stretching method $^{74}$.

Surface wave depth sensitivity. As surface waves are mainly composed of shear waves ( $\mathrm{S}$ waves), active seismic acquisitions on the landslide were used to measure the velocity of the $S$ waves. The surface wave inversion technique was applied in the Geopsy software (http://www.geopsy.org) with signals generated by dropping a mass of $80 \mathrm{~kg}$ from a height of $2 \mathrm{~m}$ using a tripod (see Supplementary Fig. 11). The model obtained by inversion gave a first layer of $\sim 8-12 \mathrm{~m}$ with $\mathrm{S}$ waves traveling at around $110 \mathrm{~m} / \mathrm{s}$. Below, lies another layer composed of lacustrine deposits, where the S-wave velocity was close to $350 \mathrm{~m} / \mathrm{s}$ (see supplementary Note 2 for further details).

From this model, it was possible to study the Rayleigh wave sensitivity as a function of depth and frequency using the gpdc package available in the Geopsy software. Perturbation of the Rayleigh wave velocity observed at the surface was examined by imposing a decrease of $14 \%$ of the shear wave velocity over a $50-\mathrm{cm}$ layer at different depths to the reference model (Supplementary Fig. 13 and supplementary Note 3). The surface waves filtered between 3 and $8 \mathrm{~Hz}$ were estimated to be sensitive to depths down to $40 \mathrm{~m}$, i.e., within the unstable mass of the soil.

Velocity of $\mathbf{P}$ and $\mathbf{S}$ waves as a function of saturation. In order to model the impact of the variation of the water table height upon the surface wave velocities, we used the Biot-Gassmann equations $s^{45}$ as done in other studies ${ }^{46,75,76}$. These equations give the velocity of $\mathrm{Vp}$ and $\mathrm{Vs}$ as a function of the porosity and their fluid saturation. The velocity of the lacustrine deposits previously obtained thanks to the geophysical survey (see SI), i.e., $\mathrm{Vp}=1900 \mathrm{~m} \cdot \mathrm{s}^{-1}$ and $\mathrm{Vp}=350 \mathrm{~m} \cdot \mathrm{s}^{-1}$, were used as fitting values to set the equations parameters (the porosity and the consolidation coefficient) and calibrate them when the soil is completely saturated. As no values of the bulk and shear modulus were obtained on the landslide, we used as input the bulk and shear modulus of the feldspar plagioclase, one of the main minerals present in the landslide ${ }^{77}$, i.e., $\mathrm{Ks}=75.6 \mathrm{MPa}$ and $\mathrm{Gs}=25.6 \mathrm{GPa}^{78}$. We fit the P-and S-wave velocities by choosing a porosity of the soil of $35 \%$ and a compaction coefficient of 120. Then the gpdc package available in the Geopsy software is again used to estimate the Rayleigh wave velocity variations as a function of the frequency for undrained loading (see Supplementary Fig. 14b and the supplementary Note 4 ) or when a water table at $10-\mathrm{m}$ depth experiences a $1-\mathrm{m}$ variation. This last model predicts a variation of around $0.04 \%$ between 3 and $8 \mathrm{~Hz}$. The sign of the variations will depend on the direction of the water table variation.

Earthquake ground motion approximation. The seismic shaking intensity was estimated by computing the PGV, which is one indicator of seismic ground motion. The PGV can be computed directly from the signal measured by the seismometer installed on the landslide. However, a large number of earthquakes with magnitudes ranging between Ml3.5 and Ml7.1 saturated the signal registered by the seismometer. Consequently, the PGV was not always accessible, in particular for the largest and/or nearest earthquakes. For those events, the PGV was computed from Ground Motion Prediction Equations (GMPE). However, no GMPE was available for Peru alone ${ }^{79}$ and most GMPEs are based on moment magnitude, whereas the magnitudes given by the Peruvian Geophysical Institute correspond to local magnitudes. Two classical GMPEs ${ }^{80,81}$ were therefore compared and the fit between the estimated and the measured PGV was determined for unsaturated signals. The used GMPEs were developed for earthquakes with magnitudes ranging between Mw5 and Mw7.6 for the first model ${ }^{81}$ and between Mw4 and Mw8 for the second one ${ }^{80}$. Their maximum distance validity are, respectively, 100 and $400 \mathrm{~km}$. We chose to push the limit of the valid magnitude for both models by comparing measured and estimated PGV for earthquakes between 3.5 and 8 , and to see their efficiency in our area when using local magnitudes instead of moment magnitudes. Concerning the maximum distance, we used all earthquakes that did not saturate the landslide within a radius of $400 \mathrm{~km}$ from the landslide, corresponding to the maximum distance of the second GMPE ${ }^{80}$. These limits allowed us to compare PGV values from a catalog of 348 events between February 2016 and November 2018.

Finally, the PGV of all these events was computed for the two horizontal components: North $\left(\mathrm{PGV}_{\mathrm{N}}\right)$ and East $\left(\mathrm{PGV}_{\mathrm{E}}\right)$. The final measured PGV is defined as follows: $\mathrm{PGV}_{\text {measured }}=\sqrt{\mathrm{PGV}_{\mathrm{N}} * \mathrm{PGV}_{\mathrm{E}}}$.

The fit between measured an estimated PGV (see Supplementary Fig. 9), shows a better result using the GMPE from Akkar and Boomer ${ }^{81}$ for our dataset. Therefore, the PGVs were taken directly from the seismic signal when the seismometer did not saturate, and from the Akkar and Boomer GMPE when the Maca station saturated.

The PGV was considered to have no uncertainties when determined from recorded seismic signals. However, the uncertainty on the PGV obtained from GMPEs could be considerable. This uncertainty was estimated by computing the standard deviation of the relative error between the PGV measured and the approximated values when both were available. A final relative error of $56 \%$ was obtained in the case where the PGV had to be approximated using the Akkar and Boomer GMPE ${ }^{81}$.

Meteorological data. Daily precipitations, daily minimum and maximum temperatures were recorded at the SENAMHI meteorological station in Madrigal, $5 \mathrm{~km}$ west of the Maca landslide and at the same elevation. Precipitations, at the valley scale, are homogeneous ${ }^{24}$ so that meteorological data collected in Madrigal are representative of those at the landslide location. However, although precipitations are known to be similar, no specific studies have compared the temperature between Madrigal and Maca. As the two villages are at the same elevation $(3200 \mathrm{~m}$ asl), the Madrigal temperature was used as a proxy for the temperature in Maca.

Effective precipitation. For this study, the effective precipitation was defined as the daily cumulated precipitation minus evapotranspiration $\left(\mathrm{ET}_{0}\right)$ that combines two parameters: transpiration and evaporation. The $\mathrm{ET}_{0}$ can be computed in several ways. Due to the limited number of meteorological parameters available, the Hargreaves method ${ }^{82}$ was used as it requires only simple meteorological data, such as daily precipitation, daily minimum and maximum temperature ${ }^{83}$. This method has also been demonstrated to be globally valid ${ }^{49,50}$. We used a method described in a crop-evapotranspiration guideline ${ }^{84}$, using the temperature and precipitation information measured in Madrigal. $\mathrm{ET}_{0}$ was then multiplied by a factor, $\mathrm{Kc}$, with a value of 0.3 (corresponding to a soil without much vegetation) to obtain the crop evapotranspiration under standard conditions, ETc.

\section{Data availability}

Data are available from the corresponding author upon reasonable request.

\section{Code availability}

Methods are illustrated through text and figure captions and codes are available from the corresponding author upon request.

Received: 11 June 2019; Accepted: 17 December 2019; Published online: 07 February 2020

\section{References}

1. Keefer, D. K. Landslides caused by earthquakes. Geol. Soc. Am. Bull. 95, 406-421 (1984).

2. Chigira, M., Wu, X., Inokuchi, T. \& Wang, G. Landslides induced by the 2008 Wenchuan earthquake, Sichuan, China. Geomorphology 118, 225-238 (2010).

3. Harp, E. L., Jibson, R. W. \& Keefer, D. K. Instrumentation of the weeks creek landslide for improved landslide monitoring. AGU Fall Meet. Abstr. 1, 0947 (2002).

4. Keefer, D. K. Investigating landslides caused by earthquakes-a historical review. Surv. Geophysics 23, 473-510 (2002).

5. Lacroix, P., Perfettini, H., Taipe, E. \& Guillier, B. Co- and Postseismic motion of a landslide; observations, modelling and analogy with tectonic faults. Geophys. Res. Lett. https://doi.org/10.1002/2014GL061170 (2014).

6. Meunier, P., Hovius, N. \& Haines, A. J. Regional patterns of earthquaketriggered landslides and their relation to ground motion. Geophys. Res. Lett. 34, 5 (2007)

7. Newmark, N. M. Effects of earthquakes on dams and embankments. Geotechnique 15, 139-159 (1965).

8. Meunier, P., Hovius, N. \& Haines, J. A. Topographic site effects and the location of earthquake induced landslides. Earth Planet. Sci. Lett. 275, 221-232 (2008).

9. Sassa, K., Fukuoka, H., Wang, G. \& Ishikawa, N. Undrained dynamic-loading ring-shear apparatus and its application to landslide dynamics. Landslides $\mathbf{1}$, 7-19 (2004).

10. Sassa, K., Fukuoka, H., Wang, F. \& Wang, G. in Progress in Landslide Science (eds. Sassa, K., Fukuoka, H., Wang, F. \& Wang, G.) 193-207 (Springer Berlin Heidelberg, 2007).

11. $\mathrm{Xu}, \mathrm{Q}$. et al. Observations from the large, rapid Yigong rock slide-debris avalanche, southeast Tibet. Can. Geotech. J. 49, 589-606 (2012).

12. King, J., Loveday, I. \& Schuster, R. L. The 1985 Bairaman landslide dam and resulting debris flow, Papua New Guinea. Q. J. Eng. Geol. Hydrogeol. 22, 257-270 (1989).

13. Gratchev, I. B., Sassa, K., Osipov, V. I. \& Sokolov, V. N. The liquefaction of clayey soils under cyclic loading. Eng. Geol. 86, 70-84 (2006).

14. Jibson, R. W., Prentice, C. S., Borissoff, B. A., Rogozhin, E. A. \& Langer, C. J. Some observations of landslides triggered by the 29 April 1991 Racha earthquake, Republic of Georgia. Bull. Seismological Soc. Am. 84, 963-973 (1994).

15. Rojstaczer, S. \& Wolf, S. Permeability changes associated with large earthquakes: an example from Loma Prieta, California. Geology 20, 211-214 (1992). 
16. Wang, C. \& Chia, Y. Mechanism of water level changes during earthquakes: near field versus intermediate field. Geophys. Res. Lett. 35, L12402 (2008).

17. Marc, O., Hovius, N., Meunier, P., Uchida, T. \& Hayashi, S.-I. Transient changes of landslide rates after earthquakes. Geology https://doi.org/10.1130/ G36961.1 (2015)

18. Bontemps, N., Lacroix, P. \& Doin, M.-P. Inversion of deformation fields timeseries from optical images, and application to the long term kinematics of slow-moving landslides in Peru. Remote Sens. Environ. 210, 144-158 (2018).

19. Scheingross, J. S. et al. Fault-zone controls on the spatial distribution of slowmoving landslides. GSA Bull. 125, 473-489 (2013).

20. Peter, M., Anderson, R. S. \& Prestrud, A. S. Tectonics, fracturing of rock, and erosion. J. Geophys. Res.: Earth Surface 112, F03014 (2007).

21. Clarke, B. A. \& Burbank, D. W. Bedrock fracturing, threshold hillslopes, and limits to the magnitude of bedrock landslides. Earth Planet. Sci. Lett. 297, 577-586 (2010).

22. Wieczorek, G. F. \& Guzzetti, F. A review of rainfall thresholds for triggering landslides. in Proc. of the EGS Plinius Conference, Maratea, Italy 407-414 (1999).

23. Caine, $\mathrm{N}$. The rainfall intensity: duration control of shallow landslides and debris flows. Geogr. Ann. A 62, 23-27 (1980).

24. Zerathe, S. et al. Morphology, structure and kinematics of a rainfall controlled slow-moving Andean landslide, Peru: The Maca slow-moving Andean landslide. Earth Surf. Process. Landf. 41, 1477-1493 (2016).

25. Hungr, O., Leroueil, S. \& Picarelli, L. The Varnes classification of landslide types, an update. Landslides 11, 167-194 (2014).

26. Antayhua, Y., Tavera, H., Bernal, I., Palza, H. \& Aguilar, V. Localización hipocentral y características de la fuente de los sismos de maca (1991), Sepina (1992) y cabanaconde (1998) región del volcán sabancaya (Arequipa). Boletin de. la Soc. Geologica del. Peru. 93, 63-72 (2002).

27. Chlieh, M. et al. Interseismic coupling and seismic potential along the Central Andes subduction zone. J. Geophys. Res. 116, B12405 (2011).

28. Handwerger, A. L., Roering, J. J. \& Schmidt, D. A. Controls on the seasonal deformation of slow-moving landslides. Earth Planet. Sci. Lett. 377-378, 239-247 (2013).

29. Coe, J. A. et al. Seasonal movement of the Slumgullion landslide determined from Global Positioning System surveys and field instrumentation, July 1998-March 2002. Eng. Geol. 68, 67-101 (2003).

30. Iverson, R. M. \& Major, J. J. Rainfall, ground-water flow, and seasonal movement at Minor Creek landslide, northwestern California: physical interpretation of empirical relations. Geol. Soc. Am. Bull. 99, 579-594 (1987).

31. Van Asch, Th. W. J., Buma, J. \& Van Beek, L. P. H. A view on some hydrological triggering systems in landslides. Geomorphology 30, 25-32 (1999).

32. Crozier, M. J. Prediction of rainfall-triggered landslides: a test of the antecedent water status model. Earth Surf. Process. Landforms: J. Br. Geomorphological Res. Group 24, 825-833 (1999).

33. Gabet, E. J., Burbank, D. W., Putkonen, J. K., Pratt-Sitaula, B. A. \& Ojha, T. Rainfall thresholds for landsliding in the Himalayas of Nepal. Geomorphology 63, 131-143 (2004)

34. Lacroix, P., Berthier, E. \& Maquerhua, E. T. Earthquake-driven acceleration of slow-moving landslides in the Colca valley, Peru, detected from Pléiades images. Remote Sens. Environ. 165, 148-158 (2015).

35. Roering, J. J. et al. Beyond the angle of repose: a review and synthesis of landslide processes in response to rapid uplift, Eel River, Northern California. Geomorphology 236, 109-131 (2015).

36. Jongmans, D., Bièvre, G., Schwartz, S., Renalier, F. \& Beaurez, N. Geophysical investigation of the large Avignonet landslide in glaciolacustrine clays in the Trièves area (French Alps). Eng. Geol. 109, 45-56 (2009).

37. Evans, S. G. Landslides and surficial deposits in urban areas of British Columbia: a review. Can. Geotech. J. 19, 269-288 (1982).

38. Jackson, L. E. Landslides and landscape evolution in the Rocky Mountains and adjacent Foothills area, southwestern Alberta, Canada. Catastrophic Landslides: Eff., Occurrence, Mechanisms, Geol. Soc. Am. Rev. Eng. Geol. 15, 325-344 (2002).

39. Kohv, M., Talviste, P., Hang, T. \& Kalm, V. Retrogressive slope failure in glaciolacustrine clays: Sauga landslide, western Estonia. Geomorphology 124, 229-237 (2010).

40. Brenguier, F. et al. Postseismic relaxation along the san andreas fault at parkfield from continuous seismological observations. Science 321, 1478-1481 (2008).

41. Mainsant, G. et al. Ambient seismic noise monitoring of a clay landslide: toward failure prediction: seismic noise monitoring of a landslide. J. Geophys. Res.: Earth Surface 117, F01030 (2012).

42. Snieder, R. \& Larose, E. Extracting Earth's elastic wave response from noise measurements. Annu. Rev. Earth Planet. Sci. 41, 183-206 (2013).

43. Larose, E. et al. Environmental seismology: What can we learn on earth surface processes with ambient noise? J. Appl. Geophysics 116, 62-74 (2015).

44. O’Brien, G. A., Cox, S. C. \& Townend, J. Spatially and temporally systematic hydrologic changes within large geoengineered landslides, Cromwell Gorge, New Zealand, induced by multiple regional earthquakes. J. Geophys. Res.: Solid Earth 121, 8750-8773 (2016).
45. Pride, S. R. in Hydrogeophysics: Wter Science and Technilogy Library 253-290 (2005).

46. Voisin, C., Garambois, S., Massey, C. \& Brossier, R. Seismic noise monitoring of the water table in a deep-seated, slow-moving landslide. Interpretation $\mathbf{4}$, SJ67-SJ76 (2016).

47. Gassenmeier, M. et al. Field observations of seismic velocity changes caused by shaking-induced damage and healing due to mesoscopic nonlinearity. Geophys J. Int. 204, 1490-1502 (2016).

48. Richter, T., Sens-Schönfelder, C., Kind, R. \& Asch, G. Comprehensive observation and modeling of earthquake and temperature-related seismic velocity changes in northern Chile with passive image interferometry. J. Geophys. Res.: Solid Earth 119, 4747-4765 (2014).

49. Ueno, K., Kuroda, S., Hori, T. \& Tatsuoka, F. Elastic shear modulus variations during undrained cyclic loading and subsequent reconsolidation of saturated sandy soil. Soil Dyn. Earthq. Eng. 116, 476-489 (2019).

50. Li, Y.-G., Chen, P., Cochran, E. S., Vidale, J. E. \& Burdette, T. Seismic evidence for rock damage and healing on the San Andreas fault associated with the 2004 M 6.0 Parkfield earthquake. Bulletin of the Seismological Society of America 96, S349-S363 (2006).

51. Viens, L., Denolle, M. A., Hirata, N. \& Nakagawa, S. Complex near-surface rheology inferred from the response of greater Tokyo to strong ground motions. J. Geophys. Res.: Solid Earth 123, 5710-5729 (2018).

52. Lyakhovsky, V., Ben-Zion, Y. \& Agnon, A. Distributed damage, faulting, and friction. J. Geophys. Res.: Solid Earth 102, 27635-27649 (1997).

53. TenCate, J. A. Slow dynamics of earth materials: an experimental overview. Pure Appl. Geophys. 168, 2211-2219 (2011).

54. Bièvre, G., Jongmans, D., Winiarski, T. \& Zumbo, V. Application of geophysical measurements for assessing the role of fissures in water infiltration within a clay landslide (Trièves area, French Alps). Hydrological Process. 26, 2128-2142 (2012)

55. Krzeminska, D. M., Bogaard, T. A., Malet, J.-P. \& van Beek, L. P. H. A model of hydrological and mechanical feedbacks of preferential fissure flow in a slowmoving landslide. Hydrol. Earth Syst. Sci. 17, 947-959 (2013).

56. Krzeminska, D. M., Bogaard, T. A., Van Asch, T. W. \& Van Beek, L. P. H. A conceptual model of the hydrological influence of fissures on landslide activity. Hydrol. Earth Syst. Sci. 16, 1561-1576 (2012).

57. Stumpf, A., Malet, J.-P., Kerle, N., Niethammer, U. \& Rothmund, S. Imagebased mapping of surface fissures for the investigation of landslide dynamics. Geomorphology 186, 12-27 (2013).

58. Snieder, R., Sens-Schönfelder, C. \& Wu, R. The time dependence of rock healing as a universal relaxation process, a tutorial. Geophys. J. Int. 208, 1-9 (2016).

59. Chang, T.-S. \& Woods, R. D. Effect of particle contact bond on shear modulus. J. Geotech. Eng. 118, 1216-1233 (1992).

60. Wistuba, M. et al. Can low-magnitude earthquakes act as a triggering factor for landslide activity? Examples from the Western Carpathian Mts, Poland. CATENA 171, 359-375 (2018).

61. Durand, V. et al. On the link between external forcings and slope instabilities in the Piton de la Fournaise Summit Crater, Reunion Island. J. Geophys. Res.: Earth Surf. 123, 2422-2442 (2018).

62. Lin, C.-W. et al. Impact of Chi-Chi earthquake on the occurrence of landslides and debris flows: example from the Chenyulan River watershed, Nantou, Taiwan. Eng. Geol. 71, 49-61 (2004).

63. Zhang, S. \& Zhang, L. M. Impact of the 2008 Wenchuan earthquake in China on subsequent long-term debris flow activities in the epicentral area. Geomorphology 276, 86-103 (2017).

64. TenCate, J. A., Smith, E. \& Guyer, R. A. Universal slow dynamics in granular solids. Phys. Rev. Lett. 85, 1020 (2000).

65. Herring, T. A., King, R. W. \& McClusky, S. C. GAMIT Reference Manual: GPS Analysis at MIT, Release 10.4. (Mass. Inst. of Technol., Cambridge, 2010).

66. Boehm, J., Werl, B. \& Schuh, H. Troposphere mapping functions for GPS and very long baseline interferometry from European Centre for Medium-Range Weather Forecasts operational analysis data. J. Geophys. Res.: Solid Earth 111, B02406 (2006).

67. Nocquet, J.-M. PYACS: a set of Python tools for GPS analysis and tectonic modelling. in Colloque G2 2017, Geodesy-Rheology (2017).

68. Altamimi, Z., Collilieux, X. \& Métivier, L. ITRF2008: an improved solution of the international terrestrial reference frame. J. Geod. 85, 457-473 (2011).

69. Nocquet, J.-M. et al. Motion of continental slivers and creeping subduction in the northern Andes. Nat. Geosci. 7, 287-291 (2014).

70. Jara, J., Socquet, A., Marsan, D. \& Bouchon, M. Long-term interactions between intermediate depth and shallow seismicity in North Chile subduction zone. Geophys. Res. Lett. 44, 9283-9292 (2017).

71. Moreau, L. et al. Improving ambient noise correlation functions with an SVDbased Wiener filter. Geophys J. Int 211, 418-426 (2017).

72. Sens-Schönfelder, C. \& Wegler, U. Passive image interferometry and seasonal variations of seismic velocities at Merapi Volcano, Indonesia. Geophys. Res. Lett. 33, L21302 (2006). 
73. Lobkis, O. I. \& Weaver, R. L. Coda-wave interferometry in finite solids: recovery of P-to-S conversion rates in an elastodynamic billiard. Phys. Rev. Lett. 90, 254302 (2003).

74. Weaver, R. L., Hadziioannou, C., Larose, E. \& Campillo, M. On the precision of noise correlation interferometry. Geophys. J. Int. 185 1384-1392 (2011).

75. Dupuy, B., Garambois, S. \& Virieux, J. Estimation of rock physics properties from seismic attributes-Part 1: Strategy and sensitivity analysis. Geophysics 81, M35-M53 (2016)

76. Dupuy, B. et al. Estimation of rock physics properties from seismic attributes -Part 2: Applications. Geophysics 81, M55-M69 (2016).

77. Kukulak, J., Paulo, A. \& Kalicki, T. Lithology of lacustrine deposits in the Colca Valley. J. South Am. Earth Sci. 69, 152-170 (2016).

78. Woeber, A. F., Katz, S. \& Ahrens, T. J. Elasticity of selected rocks and minerals. Geophysics 28, 658-663 (1963).

79. Douglas, J. Ground motion prediction equations 1964-2018. Review, University of Strathclyde, Glasgow (2018).

80. Boore, D. M. \& Atkinson, G. M. Boore-Atkinson NGA ground motion relations for the geometric mean horizontal component of peak and spectral ground motion parameters. PEER Report 2007/01 110 (2007).

81. Akkar, S. \& Bommer, J. J. Empirical equations for the prediction of PGA PGV, and spectral accelerations in Europe, the Mediterranean Region, and the Middle East. Seismological Res. Lett. 81, 195-206 (2010).

82. Hargreaves, G. L., Hargreaves, G. H. \& Riley, J. P. Agricultural benefits for Senegal River basin. J. Irrig. Drain. Eng. 111, 113-124 (1985).

83. Hargreaves, G. H. \& Samani, Z. Reference crop evapotranspiration from temperature. Appl. Eng. Agric. 1, 96-99 (1985).

84. Allen, R. G., Pereira, L. S., Raes, D. \& Smith, M. Crop evapotranspirationGuidelines for computing crop water requirements-FAO Irrigation and drainage paper 56. FAO, Rome 300, D05109 (1998).

\section{Acknowledgements}

This experiment was funded by an SEG Geophysicists Without Borders grant, a grant from ESA through the Alcantara project "Monitoring and Detection of Landslides from optical Images time-Series" (ESA 15/P26), a CNES/TOSCA grant, and a CNRS/INSU grant. This work was supported by a grant from Labex OSUG@2020 (Investissements d'avenir ANR10 LABEX56). The principal investigator, Noélie Bontemps, is funded by a CNES doctoral fellowship. The authors are grateful for support from the INGEMMET, J. C. Villegas from the Instituto Geofisico del Peru (IGP), the International Plate Boundary Observatory Chile (IPOC, www.ipoc-network.org), Laboratoire International Associé "Montessus de Ballore" (www.lia-mb.net), Central Andean Tectonic Observatory Geodetic Array (CAnTO, http://www.tectonics.caltech.edu/resources/continuous_gps.html), and thank the Centro Sismologico Nacional (CSN, www.csn.uchile.cl) for making the raw GPS data available. Jorge Jara thanks the European Research Council (ERC) for funding under the European Union's Horizon 2020 research and innovation program (grant agreement 758210, project Geo4D). Additional financial support came from the ANR GEO3iLLAB.

\section{Author contributions}

P.L., E.L., E.T. and N.B. installed the seismic and GPS station on the Maca landslide and performed the field experiments. E.T. collected the data every three month in the field. N. B. processed the seismic data and J.J. and N.B. processed the GPS data. N.B. prepared the Figures. P.L., N.B., and E.L. interpreted the data and wrote the paper. P.L. and E.L. designed and coordinated the study.

\section{Competing interests}

The authors declare no competing interests.

\section{Additional information}

Supplementary information is available for this paper at https://doi.org/10.1038/s41467020-14445-3.

Correspondence and requests for materials should be addressed to N.B.

Peer review information Nature Communications thanks the anonymous reviewers for their contribution to the peer review of this work. Peer reviewer reports are available.

Reprints and permission information is available at http://www.nature.com/reprints

Publisher's note Springer Nature remains neutral with regard to jurisdictional claims in published maps and institutional affiliations.

(c) (i) Open Access This article is licensed under a Creative Commons By Attribution 4.0 International License, which permits use, sharing, adaptation, distribution and reproduction in any medium or format, as long as you give appropriate credit to the original author(s) and the source, provide a link to the Creative Commons license, and indicate if changes were made. The images or other third party material in this article are included in the article's Creative Commons license, unless indicated otherwise in a credit line to the material. If material is not included in the article's Creative Commons license and your intended use is not permitted by statutory regulation or exceeds the permitted use, you will need to obtain permission directly from the copyright holder. To view a copy of this license, visit http://creativecommons.org/ licenses/by/4.0/.

(c) The Author(s) 2020 